\title{
Response to diphtheria booster vaccination in healthy adults: vaccine trial
}

\author{
Akke Vellinga, Pierre Van Damme, Els Joossens, Herman Goossens
}

The diphtheria epidemic in eastern Europe and the worldwide increase in diphtheria morbidity have sparked discussion on whether people in western Europe are adequately protected. ${ }^{12}$ In western Europe, the effectiveness of long term protection afforded by immunisation programmes is under debate.

In Belgium, the national immunisation programme against diphtheria was introduced in 1959. Vaccination was recommended for all infants, and a catch up programme for children up to the age of 15 years was also instituted. The programme comprises four doses of toxoid, given at age 3, 4, 5, and 15 months. The vaccine is a combination of diphtheria, pertussis, and tetanus toxins, and $95 \%$ of children are covered. ${ }^{3}$ We evaluated the effectiveness of the current recommended adult booster immunisation of a single, low dose diphtheria vaccine.

\section{Subjects, methods, and results}

Altogether 176 volunteers were recruited from the employees of a company in Flanders in 1997. We focused on recruiting subjects aged 33-50 years as they had been the first to be vaccinated in the national programme and we expected to find a high proportion of subjects who were susceptible to infection in this group. ${ }^{3}$ After being screened and answering questions about previous vaccinations, subjects gave a blood sample and received an intramuscular dose of vaccine in the deltoid region (Tedivax pro adulto $(>4 \mathrm{IU}$ of diphtheria toxin and $>40$ IU of tetanus toxin); SmithKline Beecham Biologicals, Belgium). A follow up appointment was made for one month later. The laboratory methods used have been described. ${ }^{3}$ All samples taken before and after immunisation were analysed in the same run in one laboratory.

Antitoxin titres of $<0.01 \mathrm{IU} / \mathrm{ml}$ (class 1) indicate susceptibility to diphtheria, whereas titres $\geqslant 0.1 \mathrm{IU} / \mathrm{ml}$ (class 3) afford protection. At titres between $\geqslant 0.01$ $\mathrm{IU} / \mathrm{ml}$ and $<0.1 \mathrm{IU} / \mathrm{ml}$ (class 2), protection is of limited duration. ${ }^{4}$

Statistical analysis was performed with SPSS for Windows 9.0. Differences in age and weight in the groups were compared by analysis of variance and $t$ test; the $\chi^{2}$ test was used to compare gender differences.

The study population comprised 96 men and 80 women with a mean (SD) age of 41.2 (4.2) years. As a result of the booster vaccination, $76 \%$ obtained protec- tion (class 3), $5 \%$ had limited protection (class 2), and $19 \%$ remained susceptible (class 1) (table). Age was the only significant factor determining the serological class before booster vaccination $(F=5.583, \mathrm{df}=2, \mathrm{P}<0.005)$ and after it $(F=7.377, \mathrm{df}=2, \mathrm{P}<0.001)$. Weight and sex seemed to have no effect. All subjects whose titres were in class 2 before the booster achieved class 3 status afterwards. Nine (13\%) subjects in class 1 moved to class 2 and $27(39 \%)$ to class 3 after the booster; the rest stayed in class $1(48 \%)$. The 42 subjects who remained in classes 1 or 2 after booster vaccination were significantly older than the subjects who moved from class 1 or 2 to class 3 (43.3 (4.1) years $v 41.1$ (4.3 years); $t=2.579, \mathrm{df}=98, \mathrm{P}<0.05)$.

\section{Comment}

The single adult diphtheria booster is insufficient to obtain adequate protection. In published reports, at least $70 \%$ of the adults who receive a booster dose of diphtheria toxoid achieve protection ${ }^{5}$; in our study, $76 \%$ did: this means that $24 \%$ of our subjects did not respond adequately, whereas $42 \%$ of those who are not protected beforehand do not obtain full protection.

Age is a main determinant of long term protection against diphtheria induced by vaccination. However, the antitoxin titres achieved by some of the younger people who had been vaccinated in childhood were not satisfactory. Because of this, public health recommendations based on age cannot be formulated.

Contributors: AV undertook statistical analysis, and wrote the article. PVD designed and coordinated this study and edited the paper. EJ carried out the blood sampling and data collection. $\mathrm{HJ}$ was responsible for the laboratory analysis. PVD is guarantor.

Funding: Centre for the Evaluation of Vaccination.

Competing interests: None declared.

1 Prospero E, Raffo M, Bagnoli M, Appignanesi R, D'Errico MM. Diphtheria: epidemiological update and review of prevention and control strategies. Eur J Epidemiol 1997;13:527-34.

2 Hardy IR, Dittmann S, Sutter RW. Current situation and control strategies for resurgence of diphtheria in newly independent states of the former Soviet Union. Lancet 1996;347:1739-44.

3 Matheï C, Van Damme P, Bruynseels P, Goossens H, Vranckx R, Meheus A. Diphtheria immunity in Flanders. Eur J Clin Microbiol Infect Dis 1997;16:631-6

4 Dixon JMS. Diphtheria. In: Topley WWC, Parker MT, Collier L, Wilson G eds. Topley and Wilson's principles of bacteriology, virology and immunity. Bacterial diseases. London: Edward Arnold, 1990:56-75.

5 Galazka AM, Robertson SE. Immunisation against diphtheria with special emphasis on immunisation of adults. Vaccine 1996;14:845-57.

(Accepted 29 July 1999)

\author{
Centre for the \\ Evaluation of \\ Vaccination, \\ Department of \\ Epidemiology and \\ Community \\ Medicine, \\ University of \\ Antwerp, 2610 \\ Antwerp, Belgium \\ Akke Vellinga \\ epidemiologist \\ Pierre Van Damme \\ postdoctoral \\ researcher \\ Els Joossens \\ assistant \\ Laboratory of \\ Microbiology, \\ University of \\ Antwerp \\ Herman Goossens \\ professor \\ Correspondence to: \\ P Van Damme \\ pvdamme@uia.ua. \\ ac.be
}

BMJ 2000;320:217

Age and antitoxin titre class before and after booster immunisation against diphtheria. Values are numbers (percentages) of subjects

\begin{tabular}{|c|c|c|c|c|c|c|c|}
\hline \multirow{2}{*}{$\begin{array}{l}\text { Age group } \\
\text { (years) }\end{array}$} & \multirow[b]{2}{*}{ No of subjects } & \multicolumn{3}{|c|}{ Before booster } & \multicolumn{3}{|c|}{ After booster } \\
\hline & & Class 1 & Class 2 & Class 3 & Class 1 & Class 2 & Class 3 \\
\hline$<40$ & 79 & $21(31)$ & $18(58)$ & $40(53)$ & $5(15)$ & $2(22)$ & $72(54)$ \\
\hline$\overline{40-44}$ & 56 & $25(36)$ & $5(16)$ & $26(34)$ & $14(42)$ & $5(56)$ & $37(27)$ \\
\hline$\geqslant 45$ & 41 & $23(33)$ & $8(26)$ & $10(13)$ & $14(42)$ & $2(22)$ & $25(19)$ \\
\hline Total & 176 & $69(39)$ & $31(18)$ & $76(43)$ & $33(19)$ & $9(5)$ & $134(76)$ \\
\hline
\end{tabular}

Class 1=susceptibility to infection; class 2=limited protection; class $3=$ protection. 